\title{
Supporting the Production of Graphic Symbol Combinations by Children with Limited Speech: A Comparison of Two AAC systems
}

\author{
Kerstin M. Tönsing \\ University of Pretoria
}

\author{
Author address \\ Centre for Augmentative and Alternative Communication, \\ Communication Pathology Building \\ University of Pretoria \\ Hatfield \\ 0002 \\ Pretoria \\ South Africa
}

Correspondence regarding this article should be addressed to Kerstin Tönsing, email:

kerstin.tonsing@up.ac.za, tel.: +27 12420 2001; fax: +27 865100841

\begin{abstract}
The aim of this study was to compare the efficacy with which the use of a speech generating device (Apple Pad $^{\mathrm{TM}}$ with GoTalk Now ${ }^{\mathrm{TM}}$ application) versus a communication board promoted the production of two-symbols combinations (agent-action and attribute-entity combinations) by children limited speech within a shared story reading context. Four children between the ages of 6;8 (years;months) and 11;4 with severe motor speech disorders and a variety of developmental
\end{abstract}


disabilities participated in the study. An adapted alternating treatment design was used. All four participants showed increased production of two-symbol combinations in both intervention conditions. The Wilcoxon ranked pairs test did not show differences between the conditions for any participant. The results suggest that symbol combination skills can effectively be taught using either AAC system. A preference assessment indicated that all participants preferred to use the speech generating device during shared story reading.

Keywords: augmentative and alternative communication, communication board, developmental disabilities, graphic symbol combinations, shared story reading, speech generating device.

Children with limited speech often benefit from graphic symbol-based augmentative and alternative communication (AAC) systems. Graphic symbols such as Picture Communication Symbols (PCS) are typically used on non-electronicpaper-based systems such as communication boards, and also in conjunction with electronic systems such as speech generating devices (SGDs). Amongst the various factors that can influence the decision to provide a child with either or both types of systems, the efficiency with which the system can support the acquisition of a variety of expressive language skills and communication functions should certainly be considered (Schlosser 2003). The preference of both the child as well as his/her partners are other important variables in decision-making (Sigafoos, O'Reilly, Ganz, Lancioni and Schlosser 2005; Van der Meer, Sigafoos, O’Reilly and Lancioni 2011).

Gevarter et al. (2013) systematically reviewed single case research studies comparing different communication systems for individuals with developmental disabilities, amongst others those that attempted to determine the comparative efficacy with which non-electronic picture 
based systems and SGDs support specific communication outcomes. The authors noted that (a) all studies focussed on basic requesting skills requiring the use of only one symbol per response in all or at least one of the intervention conditions; and (b) most studies did not support consistent differences between electronic and non-electronic systems. One explanation for the lack of clear differences between the conditions may be that the acquisition of the requesting skills targeted in these interventions is strongly motivated by the reinforcer. Participants might be so motivated to obtain the reinforcer, that the method to obtain it loses particular relevance. The acquisition of communication functions that are not as tangibly motivated but that proceed for social and interactive reasons might be more prone to influence by the system used, as internal rather than external motivation may play a larger role (Light, Parsons and Drager 2002). Of the 31 participants that took part in the studies comparing SGDs to non-electronic AAC systems reviewed by Gevarter et al (2013), 17 had a diagnosis of autism spectrum disorder (ASD), autism or pervasive developmental disorder (PDD). Young children with these diagnoses typically are more likely to communicate in order to regulate the behavior of others (i.e., requesting or protesting), rather than for the purpose of social interaction (Wetherby, Watt, Morgan and Shumway 2007), which may explain the focus on requesting in these studies.

The use of electronic versus non-electronic systems may differentially influence the production of multi-symbol combinations (Binger, Kent-Walsh, Berens, Del Campo and Rivera, 2008). An SGD provides auditory feedback to the person using it on his/her own productions, which may facilitate language learning (Romski and Sevcik 1988;1996; Romski, Sevcik and Adamson 1997). The digital or synthetic speech generated by the SGD may reinforce the learning of symbol sequences. This may be a benefit that is particularly relevant to children who have an understanding of spoken language, whereas the receptive (spoken) language skills of the 
participants in the studies reviewed by Gevarter et al. (2013) seemed to be either not specified or at age equivalent levels of below 2 years in most cases.

Learning to produce symbol combinations has been established as an important intervention aim for many children who rely on graphic symbols for expression as this skill seems to present a particular hurdle for many of them (Binger and Light 2007, 2008; Sutton, Soto and Blockberger 2002). In typical language development, the emergence of word combinations is an important milestone, and has been described as the first step towards the development of grammar and a truly generative language system (Bates, Dale and Thal 1995). For children using graphic symbols to communicate, use of predominantly single-symbol messages can lead to overreliance on partners to interpret their message, frequent communicative breakdowns, frustration and abandonment of communicative attempts (Sutton et al. 2002).

Four single subject intervention studies particularly aimed at encouraging children with limited speech and a variety of developmental disabilities (e.g., cerebral palsy, developmental delay, ASD and multiple disabilities) to comment and/or answer questions using multi-graphic symbol messages (Binger et al. 2008; Binger, Kent-Walsh, Ewing and Taylor 2010; Nigam, Schlosser and Lloyd 2006; Tönsing, Dada and Alant 2014). In the studies by Binger et al. (2008; 2010), parents and educational assistants respectively modelled a variety of two-symbol combinations. The specific types of combinations were not specified. Nigam et al. (2006) targeted action-object combinations, while Tönsing et al. (2014) targeted agent-action, attributeentity and possessor possession combinations. Intervention in three studies entailed adult scaffolding within shared story reading activities (Binger et al. 2008; 2010; Tönsing et al. 2014). Adult scaffolding included the use of models, questions, mands and expansions. In all four studies, children increased their productions of multi-symbol messages. The AAC systems used 
by participants in these studies included either communication boards (Binger et al. 2008; Nigam et al. 2006, Tönsing et al. 2014) or SGDs (Binger et al. 2008; 2010). In the study where participants used either a communication board or an SGD (Binger et al. 2008) participants making use of SGDs with graphic symbol overlays produced the combinations quicker than participants using non-electronic communication boards; however, the small sample and potential differences between participants precluded any definite conclusions. In each of the other studies, participants either all made use of communication boards (Nigam et al. 2006; Tönsing et al. 2014) or they all made use of SGDs (Binger et al. 2010). From these studies it is therefore not clear whether use of SGDs rather than communication boards may encourage the production of graphic symbol combinations more effectively and efficiently.

Two studies compared the use of electronic and non-electronic systems in encouraging productions beyond single words from children with limited speech. Using a quasi-experimental single group pretest-posstest design, Bruno and Trembath (2006) assessed the effect of aided language input on children's syntactic performance during picture description using either their own SGD or a manual communication board given to them. On average, syntactic performance improved for the group in both conditions, although improvements were more marked in the communication board condition. Results were somewhat complicated by children who achieved ceiling level results in the pretest and by the fact that the systems being compared had inherent differences in access and navigational demands.

Van der Meer et al. (2013) investigated the efficacy of three AAC options (manual signing, picture exchange and speech generating application on the iPod or iPad ${ }^{\mathrm{TM} 1}$ ) to promote, amongst others, multi-step requesting in two children with autism spectrum disorders. Using an

\footnotetext{
${ }^{1}$ iPod and iPad are registered trademarks of Apple Inc., Cupertino, CA.
} 
alternating treatment design, the participants were taught to produce two- and three-step requests with symbols/manual signs. One participant learnt to produce two- and three-step requests, whereas the second one learnt only to produce two-step requests. Results are somewhat difficult to interpret as other communication functions involving the use of single symbols (greeting, answering questions and social etiquette) were also targeted in the same intervention. For both participants, the picture exchange condition seemed slightly more effective and efficient. Participant preference for each of the AAC systems/strategies used was also assessed. One participant preferred the iPod, whereas the other preferred the picture exchange.

Preference of the person using the system has been identified as another important variable to consider when choosing an AAC system, as it promotes self-determination and can significantly influence therapeutic and educational outcomes (Sigafoos et al. 2005). Van der Meer et al. (2011) summarised the preference assessments done in seven studies comparing SGDs with other AAC systems/strategies. Overall, most participants (67\%) preferred the SGD above other systems or strategies. Performance using the device mostly did not predict preference. Two other studies comparing SGDs and non-electronic systems also investigated team perspectives regarding their preference of system (Flores et al. 2012) or team perceptions of child preference (Boesch, Wendt, Subramanian and Hsu 2013). The perceptions of intervention teams and partners such as parents, teachers and therapists may also greatly influence the success and extend with which an AAC system is implemented, as partners play a critical role in supporting communication interactions of children using AAC, including the construction or programming, general management and implementation of aided AAC systems (Blackstone, Williams and Wilkins 2007; Kent-Walsh and McNaughton 2005; Light and Drager 2007). Their perceptions and preferences regarding these systems are likely to influence children's language 
and communication outcomes.

The current study aimed to expand the research comparing SGDs and non-electronic AAC systems in various ways. Previous comparative studies focussed mainly on the production of single symbol utterances for the purpose of requesting and the majority of participants had a diagnosis of ASD or PDD. The aim of the current study was to compare the efficacy of intervention incorporating a communication board versus an SGD on the production of multigraphic symbol comments by children with severe motor speech disorders during shared story reading. In addition, the study also aimed to assess the preferences of the children regarding these two systems, and to obtain the perspectives of intervention team members regarding their preferences. The study was conducted in South Africa, and this had various implications for the execution and also the results and interpretation of these.

\section{Method}

\section{Participants}

Participant selection. The ethical committee of the relevant higher education institution approved the study. Participants were recruited from a school for learners with special educational needs, and also from a university-based AAC consultation service. Selection criteria were as follows: (a) English receptive language skills equivalent to at least a 30-month level, as determined by the Peabody Picture Vocabulary Test - Fourth Edition (PPVT-4; Dunn and Dunn, 2007), (b) English as (one of) the languages spoken in the home and/or at least 3 years of English medium education; (c) aged 11;11 (years;months) or below in order for stories used to be appropriate; (d) limited speech (defined as less than 30\% intelligible in the 'semantic contextunfamiliar listener' condition of the Index of Augmented Speech Comprehensibility for Children (I-ASCC; Dowden, 1997); (e) able to accurately direct-select graphic symbols on a 10-item 
communication board and able to accurately access cells on a 10-item page of the GoTalk Now $^{\mathrm{TM} 2}$ application on the iPad; (f) able to correctly identify at least $90 \%$ of the graphic symbols used during intervention in response to the spoken word, with paired-associate training provided if necessary; (g) not combining graphic symbols; (h) no visual or auditory impairments that would preclude the use of graphic-symbol based AAC ; and (i) able to concentrate on a 10-minlong story. The latter three criteria were determined from parent, teacher and speech language pathologist (SLP) report.

Four children were identified and parental consent was obtained. Child assent was also obtained before screening commenced to determine whether the children complied with the selection criteria. The researcher (author) furthermore obtained background information from the parent, teacher and SLP and also administered the Peabody Picture Vocabulary Test $-4^{\text {th }}$ edition (PPVT-4; Dunn and Dunn 2007), the 'Elaborated phrases and sentences' subtest of the Test of Auditory Comprehension of Language $-3^{\text {rd }}$ edition (TACL-3; Carrow-Woolfolk 1999) as well as the Index of Augmented Speech Comprehensibility for Children (I-ASCC; Dowden 1997). The researcher also assessed the children's ability to identify the symbols used in the study. For the 10 symbols that were allocated to the SGD condition for the particular child, she provided the child with the appropriate page on the GoTalk Now application on the iPad (see description under 'Materials'). For the 10 symbols allocated to the communication board condition, she provided the child with the communication board designed for the study. For the 10 symbols allocated to the choice condition, she provided the appropriate page on the GoTalk Now application or the communication board at the first testing, and the other system during retesting. At the first testing, the child was presented with the first set of 10 symbols on either the communication board or the GoTalk Now page. The child was verbally requested to point to

\footnotetext{
${ }^{2}$ The GoTalk Now application is sold by Attainment Company, Verona, WI
} 
each of the 10 symbols in random order (e.g. Show me 'boy'). After a set of 10 symbols was tested, the next set was provided and tested, until all 30 symbols had been tested. Incorrect responses were immediately corrected, in anticipation of the next step (training). None of the participants achieved $100 \%$ correct identification, and therefore were provided with pairedassociate training of those symbols not correctly identified. The researcher pointed to the specific symbol while labelling it (e.g., This picture shows 'run'). Symbols that were taught in this way were retested and retrained up to five times. All participants achieved $100 \%$ accuracy within one to three training sessions. The researcher then retested all 30 symbols. The cut-off for inclusion in the study was $90 \%$ or more correct on the retesting of all 30 symbols. This procedure also served to determine that children could accurately access the PCS symbols on the board and activate the cells on the GoTalk Now application on the iPad. Furthermore, it served to familiarize the children with both the communication boards and the pages of the GoTalk Now application on the iPad.

All four participants met all the selection criteria. These and other participant characteristics are summarized in Table 1.

Participant 1. Participant 1 was a boy aged 11;3 with a diagnosis of cerebral palsy (spastic hemiplegia) and severe dysarthria. He attended an English-medium Junior ${ }^{3}$ Special $^{4}$ Grade 2 classroom at a public school for children with physical disabilities. He was ambulatory. His speech therapist had previously provided him with a communication book containing Picture Communication Symbols (PCS) arranged in about 5-6 categories for use in class and at home. However, the book was not often used in either context, and he communicated mostly through gestures and pointing to people and objects. He used PCS on communication boards and

\footnotetext{
${ }^{3}$ The Junior phase in primary school refers to the first three years of official schooling (Grades 1-3).

${ }^{4}$ The Special stream at this particular school made use of a modified curriculum with assessment standards that were lower than those of the national school curriculum.
} 


\begin{tabular}{|c|c|c|c|c|c|c|c|c|c|c|c|}
\hline \multirow[b]{2}{*}{ No } & \multirow[b]{2}{*}{$\begin{array}{l}\text { Age }^{\mathrm{a}} \\
\text { gender }\end{array}$} & \multirow[b]{2}{*}{ Disability } & \multirow{2}{*}{$\begin{array}{c}\text { Home } \\
\text { language and } \\
\text { proficiency }^{b}\end{array}$} & \multirow[b]{2}{*}{ PPVT-4 } & \multirow[b]{2}{*}{$\begin{array}{l}\text { TACL3 } \\
\text { EPS }\end{array}$} & \multirow[b]{2}{*}{$\begin{array}{c}\mathrm{KBIT}-2 \\
\mathrm{n} / \mathrm{v}\end{array}$} & \multicolumn{2}{|c|}{ I-ASCC } & \multirow{2}{*}{$\begin{array}{l}\text { Comprehension } \\
\text { of } \\
\text { targeted relations }\end{array}$} & \multirow{2}{*}{$\begin{array}{l}\text { Compr. } \\
\text { of } \\
\text { graphic } \\
\text { symbols }\end{array}$} & \multirow[b]{2}{*}{$\begin{array}{l}\text { Main communication } \\
\text { modes }\end{array}$} \\
\hline & & & & & & & $\begin{array}{c}\text { No } \\
\text { context }\end{array}$ & $\begin{array}{c}\text { Sem. } \\
\text { context }\end{array}$ & & & \\
\hline 1 & $\begin{array}{c}11 ; 3 \\
\mathrm{M}\end{array}$ & $\begin{array}{l}\text { Cerebral Palsy } \\
\text { (spastic hemiplegia) }\end{array}$ & $\begin{array}{l}\text { Southern Sotho } \\
29 / 35 \text { items } \\
(83 \%) \text { correct }^{c}\end{array}$ & $\begin{array}{c}\text { SS: } 33 \\
\text { \%ile: }<0.1 \\
\text { Age eq: } 3 ; 7\end{array}$ & Age eq: $4: 6^{\mathrm{g}}$ & $\begin{array}{c}\text { SS: } 65 \\
\text { \%ile: } 1 \\
\text { Age eq: } 5 ; 8\end{array}$ & $0 \%$ & $21 \%$ & $\begin{array}{l}\text { A-A: } 9 / 9 \\
\text { A-E: } 8 / 9\end{array}$ & $\begin{array}{l}95 \% \text { on } \\
2^{\text {nd }} \text { trial }\end{array}$ & $\begin{array}{l}\text { Vocalizations, pointing, } \\
\text { gestures, facial expression, } \\
\text { vocalizations }\end{array}$ \\
\hline 2 & $\begin{array}{c}11 ; 4 \\
\mathrm{M}\end{array}$ & Perisylvian syndrome & $\begin{array}{l}\text { Setswana, } \\
\text { English } \\
\text { Proficiency in } \\
\text { Setswana: } \\
\text { 32/35 items } \\
(91 \%) \text { correct }^{\mathrm{d}}\end{array}$ & $\begin{array}{c}\text { SS: } 20 \\
\% \text { ile: }<0.1 \\
\text { Age eq: } 2 ; 10\end{array}$ & Age eq: $3 ; 6^{\mathrm{g}}$ & $\begin{array}{c}\text { SS: } 55 \\
\text { \%ile: } 0.1 \\
\text { Age eq: } 5 ; 0\end{array}$ & $3 \%$ & $14 \%$ & $\begin{array}{l}\text { AA: } 8 / 9 \\
\text { A-E: } 9 / 9\end{array}$ & $\begin{array}{l}100 \% \text { on } \\
2^{\text {nd }} \text { trial }\end{array}$ & $\begin{array}{l}\text { Vocalizations and word } \\
\text { approximations, pointing, } \\
\text { gestures, facial expression }\end{array}$ \\
\hline 3 & $\begin{array}{c}8,0 \\
\mathrm{~F}\end{array}$ & $\begin{array}{l}\text { Glutaric aciduria type } \\
1 \text { leading to } \\
\text { encephalopathic } \\
\text { crisis at age } 3 \text {. } \\
\text { Consequent cerebral } \\
\text { palsy (spastic } \\
\text { quadriplegia) }\end{array}$ & $\begin{array}{l}\text { Setswana, } \\
\text { English, isiZulu } \\
\text { Proficiency in } \\
\text { Setswana: } \\
\text { 30/35 items } \\
(87 \%) \text { correct }^{\mathrm{e}}\end{array}$ & $\begin{array}{c}\text { SS: } 53 \\
\text { \%ile: } 0.1 \\
\text { Age eq: } 3 ; 6\end{array}$ & $\begin{array}{c}\text { SS: } 5 \\
\text { \%ile: } 5 \\
\text { Age eq: } 5.3\end{array}$ & $\begin{array}{c}\text { SS: } 68 \\
\text { \%ile: } 2 \\
\text { Age eq: } 4 ; 8\end{array}$ & $8 \%$ & $31 \%$ & $\begin{array}{l}\text { A-A:9/9 } \\
\text { A-E:7/9 }\end{array}$ & $\begin{array}{l}100 \% \text { on } \\
2^{\text {nd }} \text { trial }\end{array}$ & $\begin{array}{l}\text { Vocalizations, word } \\
\text { approximations, gestures, } \\
\text { pointing, facial expression }\end{array}$ \\
\hline 4 & $\begin{array}{c}6 ; 11 \\
\mathrm{M}\end{array}$ & $\begin{array}{l}\text { Cerebral Palsy } \\
\text { (athetoid } \\
\text { quadriplegia) }\end{array}$ & $\begin{array}{l}\text { Setswana } \\
23 / 35 \text { items } \\
(66 \%) \text { correct }^{\mathrm{f}}\end{array}$ & $\begin{array}{c}\text { SS: } 62 \\
\text { \%ile: } 1 \\
\text { Age eq: } 3 ; 9\end{array}$ & $\begin{array}{c}\text { SS: } 3 \\
\text { \%ile: } 1 \\
\text { Age eq: } 4,6\end{array}$ & $\begin{array}{c}\text { SS: } 78 \\
\text { \%ile: } 7 \\
\text { Age eq: } 4 ; 8\end{array}$ & $0 \%$ & $11 \%$ & $\begin{array}{l}\text { A-A: } 9 / 9 \\
\text { A-E: } 7 / 9\end{array}$ & $\begin{array}{l}97 \% \text { on } \\
2^{\text {nd }} \text { trial }\end{array}$ & $\begin{array}{l}\text { Vocalizations, word } \\
\text { approximations, pointing, } \\
\text { gestures, facial expression, } \\
\text { infrequent use of PCS } \\
\text { book in class }\end{array}$ \\
\hline
\end{tabular}

Note. KBIT-2 = Kaufman Brief Intelligence Test (Kaufman \& Kaufman, 2004); SS = standard score; age eq = age equivalent; A-A = agent-action; A-E = attribute-entity.

${ }^{a}$ Age at beginning of the study. ${ }^{\mathrm{b}}$ As tested by receptive subtests of Sotho Expressive Receptive Language Assessment (Bortz, 1997) for Participant 1 and the Tswana Expressive Receptive Language Assessment (Bortz, 1997) for Participants 2, 3 and 4. ${ }^{\mathrm{c}}$ A total raw score equivalent to $83 \%$ correct equates to Z score 1.35 and percentile 91.2 for 3.9-4.2-year-old isiZulu speaking children. ${ }^{\mathrm{d}}$ A total raw score equivalent to $91 \%$ correct equates to $\mathrm{Z}$ score 2.02 and percentile 97.9 for 3.9-4.2-year-old isiZulu speaking children. ${ }^{\mathrm{e}} \mathrm{A}$ total raw score equivalent to $87 \%$ correct equates to $\mathrm{Z}$ score 1.63 and percentile 94.9 for $3.9-4.2$-year-old isiZulu speaking children. ${ }^{\mathrm{f}}$ A total raw score equivalent to $66 \%$ correct equates to $\mathrm{Z}$ score 0.19 and percentile 42.4 for 3.9-4.2-year-old isiZulu speaking children. ${ }^{\mathrm{g}}$ As these participants were older than 9;11, a standard score and percentile could not be obtained. 
occasionally on a dedicated SGD (8 options) during speech therapy sessions.

Participant 2. Participant 2 was a boy aged 11;4 diagnosed with pseudobulbar palsy and severe dysarthria. He was attending an English-medium Junior Special (see Footnotes 3 and 4) Grade 3 classroom at a public school for children with physical disabilities. He was ambulatory. He had been given a communication board and book with PCS symbols containing vocabulary related to five or six categories to use in class. However, he rarely used these but rather attempted to speak. He had used a 10-symbol board at home for a while, but it was not in use at the time of the study. He had also previously used PCS on boards and occasionally on an SGD during speech therapy sessions.

Participant 3. Participant 3 was a girl aged 8;0. She had spastic quadriplegia and severe apraxia of speech as a result of glutaric aciduria type 1. She was attending Grade 1 at a Setswana-medium public school for children with severe intellectual disabilities. She was ambulatory. She had been exposed to communication boards and the GoTalk Now application on an iPad during a 2-hour consultation at a university-based AAC consultation service. She mostly used vocalizations and word approximations to communicate. At home, she also occasionally communicated by pointing to magazine images that had been pasted in an exercise book.

Participant 4. Participant 4 was a boy aged 6;11 diagnosed with athetoid quadriplegia and severe dysarthria. He was attending the English-medium Junior Special (see Footnotes 3 and 4) Grade 1 class at a public school for children with physical disabilities. He was ambulatory. He used a communication book with 64 PCS symbols in eight categories to supplement communication in class. He would try to speak or gesture first, but would fetch his file to supplement his message when needed. He pointed to one symbol at a time. He did not 
use any formal AAC system at home.

\section{Material and equipment}

The researcher developed three equivalent sets of semantic relations, each consisting of three agent-action and three attribute-entity combinations (see Table 2). According to data collected from children with typical development from various language backgrounds, these relations rank amongst the five most frequently-occurring relations in children's early two-word combinations (Brown 1973).

Table 2 : Semantic Combinations in the Three Intervention Sets

\begin{tabular}{llllll}
\hline & Set A & & \multicolumn{2}{c}{ Set C } \\
\hline Agent-action & Attribute-entity & Agent-action & Attribute-entity & Agent-action & Attribute-entity \\
\hline The dog runs & Red ball & The cat sleeps & Blue hat & The girl eats & Yellow shoe \\
Ben laughs & Dirty shirt & The cat walks & Broken & The rabbit drinks & Clean plate \\
Ben falls & Dirty pants & Sam cries & aeroplane & The rabbit sits & Clean glass \\
& & & Broken car & & \\
\hline
\end{tabular}

Each set was made up of 10 words, namely two agents, three actions, two attributes and three entities. These words were chosen with the following criteria/constraints in mind: (a) sets needed to be as equal as possible. Therefore, agents consisted of one person and one animal each, and attributes consisted of one colour and one other attribute each; (b) items needed to be represented by symbols that were easily recognizable and distinguishable so as to not add additional learning demands on participants; (c) each set of semantic combinations needed to be incorporated into a short story with a simple story line; and (d) each combination needed to be clearly recognizable from an illustration. For each set, a communication board and an identical page on the GoTalk Now application for their Pad was constructed. Each word was represented by a graphic symbol (26 PCS symbols and four symbols created in 'Paint') (see Appendix). The symbols were organized according to the Fitzgerald key (Fitzgerald 1959) and the background of each symbol was colour-coded according to category. Categories included (a) who (agents) 
coded in purple, (b) verbs (actions), coded in pink, (c) adjectives (attributes), coded in blue, and (d) what (entities), coded in yellow. The arrangement and size of the cells, boarders of cells and background colour of the page/board were identical on the board and the corresponding GoTalk Now page.

The SGD used in the study was a non-dedicated device, namely the Apple iPad 4 with the GoTalk Now application loaded onto it. Since no high quality South African synthetic child voice is yet available, a US English child voice was chosen. The pages on the GoTalk Now application were programmed in such a way that the synthetic voice produced the grammatically correct label to produce the combinations given in Table 2. The cell with the PCS symbols of $C A T$, for example, produced the synthetic voice output The cat when pressed. The application was set up in such a way that activated cells produced the voice output directly without the child having to 'build' a sentence in a sentence window first.

The researcher wrote three stories (Stories A, B and C), each containing one set of semantic combinations (see Table 2). Within a story, the combinations making up the set each appeared twice, in order to afford two opportunities to produce each combination. A graphic artist illustrated the stories. Stories A, B and C were allocated in a systematically counterbalanced fashion to the two intervention conditions (communication board versus SGD) and the choice condition for the four participants (see Table 3).

Table 3 : Allocation of Stories to Participants for the Two Intervention Conditions (Communication Board versus SGD) and the Choice Condition

\begin{tabular}{lcccc}
\hline Condition & Participant 1 & Participant 2 & Participant 3 & Participant 4 \\
\hline SGD & Story A & Story B & Story A & Story C \\
Communication board & Story B & Story A & Story C & Story B \\
Choice & Story C & Story C & Story B & Story A \\
\hline
\end{tabular}

Design 
An adapted alternating treatments design (AATD; Wolery, Gast and Hammond, 2010) was used to compare intervention using an SGD (iPad with GoTalk Now application) and a communication board respectively on the production of two-symbol combinations. The study consisted of four phases, namely baseline, intervention, preference and maintenance. The two intervention conditions (SGD and communication board) as well as a choice condition were implemented during baseline. During intervention, both intervention conditions were implemented (one session per day each) in a systematically alternating fashion, with a break of at least one hour between sessions. If the communication board condition session was conducted first on one day, the SGD condition session would be conducted first on the day following. Two of the participants commenced with the communication board condition on the first day of intervention, while the other two commenced with the SGD condition. During the preference phase, participants were offered a choice between the SGD and the communication board at the beginning of the session. One maintenance probe in each of the three conditions was conducted during the last phase.

\section{Response definition}

The dependent variable was the production of targeted two-symbol combinations within a story reading activity in response to a prompt by the researcher (first level of prompting) consisting of drawing attention to the illustration of the target combination (e.g. a blue hat) by pointing and verbalizing (e.g., Look!). A correct production in the SGD condition was defined as activating both cells containing the target concepts on the SGD in the correct order in response to the first level of prompting. An example of this would be when a participant activated the cell to produce the word "blue" and then activated the cell producing the word "hat" in response to the researcher pointing out the illustration of the blue hat. A correct production in the 
communication board condition was defined as pointing to both symbols making up the target combination in the correct order on the communication board in response to the first level of prompting. An example of this would be the participant pointing to the graphic symbol $B L U E$ followed by pointing to the graphic symbol $H A T$, to produce the combination $B L U E H A T$ in response to the researcher pointing out the illustration of the blue hat. Either response was considered correct in the baseline choice condition. During the preference phase, participants first chose between the SGD and the communication board before the session commenced, and, depending on the initial choice, either responses with the SGD or responses with the communication board as described above were counted as correct. Any response to prompts on Levels 2-5 were not taken into consideration when counting correct responses for the sake of graphing progress (see procedures).

\section{Procedures}

Sessions were scheduled on weekdays and participants were seen between four and five times a week. Participants were seen individually and the researcher conducted all the sessions. For Participants 1, 2 and 4, sessions took place at school in a separate therapy room, while Participant 3 was seen at home in the family lounge. All sessions were video-recorded. The video camera was positioned in such a way as to record both the researcher and the participant's actions clearly.

Baseline phase. Three sessions were conducted for each condition. The iPad with the GoTalk Now application open on the relevant page was available for the SGD condition, while the communication board was available for the communication board condition. Both systems were available for the story allocated to the choice condition. The system(s) was/were positioned standing upright at an angle on a table in front of the participant, within easily 
reachable distance. When both systems were available, the position of the systems was systematically varied across sessions. The researcher sat next to the participant with the story illustrations lying flat on the table in front of the participants. The researcher read the story to the participant, showing the illustrations. Before a target combination appeared in the story, the researcher drew attention to that part of the story illustration depicting the target structure (e.g. a dog running) by pointing and verbalizing (e.g. "Oh, look!”) and then pausing for up to $10 \mathrm{~s}$. Any response from the participant was acknowledged in a neutral way (e.g. "mmm”, "I see”) and the researcher continued by verbalizing the target structure and continuing to read. If no response was provided within the $10 \mathrm{~s}$, the researcher also continued by verbalizing the target structure as part of the story reading. A correct response to the prompt (Level 1 prompt) consisted of pointing to both symbols making up the target combination in the correct order on the communication board or activating both cells containing the target concepts on the SGD in the correct order.

Intervention phase. Two intervention sessions were conducted each day, one allocated to each intervention condition, with a separation of at least an hour between sessions. During one session, the story allocated to the SGD condition was read and prompts were used to elicit target symbol combinations from the participant using the SGD. During the other session, the story allocated to the communication board condition was read and prompts were used to elicit the target symbol combinations from the participant using the board. The order of sessions was counterbalanced across days and across participants. Procedures in both conditions were similar to baseline, except that additional prompts and specific feedback were given to elicit the combinations. As during baseline, the researcher read the story to the participant, showing the illustrations. The communication board or iPad was positioned within easily reachable distance 
at an angle in front of the participant. Before each target combination, the researcher employed a prompting hierarchy similarto that described in Tönsing et al. (2014). The researcher used the following prompts:

Level 1 (also used during baseline): drawing attention to the story illustration depicting the target combination (e.g., illustration of a blue hat) by pointing and verbalizing (e.g., look here, uh-oh, etc.) followed by a 10 -s pause;

Level 2: open-ended question to elicit the combination (e.g., What is happening here?) while pointing to the target illustration, followed by a 10-s pause;

Level 3: request to express the combination using the communication board or iPad (e.g., Tell me with your board/iPad) followed by a 10-s pause;

Level 4: aided model of the combination with a request to imitate this model, followed by a 10-s pause. In the communication board condition the aided model consisted of pointing to the relevant symbols on the board while verbalizing the combination (e.g., The $\{$ cat $C A T\}\{$ sleeps SLEEP $\}$ ). In the SGD condition the aided model consisted of activating the relevant cells on the iPad (e.g., “The cat sleeps.”). These models were followed by the request, Can you say that?;

Level 5: hand-over-hand assistance to help the participant point to the relevant symbols on the communication board or activate the relevant cells on the GoTalk Now ${ }^{\mathrm{TM}}$ application for the iPad to produce the combination.

Participants could respond in different ways to the prompts. The way the researcher reacted to these responses also followed a predetermined procedure. The types of responses and the researcher's reactions are set out below:

- When the participant responded to Prompts 1-5 by either pointing to both relevant symbols on the communication board or activated both relevant cells on the GoTalk Now 
Application on the iPad in the correct order, without adding additional symbols, the researcher affirmed and reinforced the response by an aided model (i.e., the researcher either pointed to the correct sequence of symbols on the communication board while verbalizing, or activated the appropriate cells on the GoTalk Now application on the iPad).

- If no response was obtained within $10 \mathrm{~s}$ of a prompt being given, the researcher gave the next prompt.

- A related nontarget response (e.g., when participants commented - mostly nonverbally - on a different aspect of the story) to Prompts 1-4 was affirmed. The participant was then redirected and given the next level of prompting (e.g., Yes, the boy will throw the ball again, but look here, what is happening here? [researcher pointed to story illustration of dog running]).

- An unintelligible response and also a response that expressed at least one of the target concepts in a different modality (e.g., miming RUN when asked about the illustration of the dog running) to Prompts 1 or 2 was followed up with Prompt 3. Unintelligible and different modality responses to Prompts 3 and 4 were followed by giving the next level of prompting.

- Incorrect aided responses were those consisting of only one symbol, or containing the target symbols in the incorrect order, or containing non-target symbols. Such responses to Prompts 1 - 3 were negated (e.g., No, we don't say only dog) and followed by Prompt 4. Incorrect responses to Prompt 4 were followed by Prompt 5.

Both a teaching and a learning criterion were set. Intervention ceased in a condition when either of the following conditions was met: once a participant's score increased to at least 10 of $12(83 \%)$ correctly produced combinations in response to the first level of prompting for two consecutive intervention sessions (with a minimum of five intervention sessions conducted in 
each condition), or after a maximum of 10 intervention sessions per condition. The researcher made the decision to cap the intervention sessions in order to prevent participants' boredom and fatigue (from repeated rereading the same story) from negatively influencing the results. Ten intervention sessions corresponded to two academic weeks (weekdays excluding weekends). If the learning criterion was reached in one condition before it was reached in another, probes continued in the mastered condition on every second day. The procedures during these probes were the same as during intervention sessions.

Preference phase. The preference phase followed immediately after the intervention phase. During this phase, the researcher told the participant that he/she would be read the third story, and then allowed him/her to choose the AAC system they wanted to use during story reading. In order to allow participants to make a choice, the board and iPad (showing the relevant GoTalk Now ${ }^{\mathrm{TM}}$ page) were positioned on the table in front of the participant, and the participant was required to point to or touch the system of his/her choice when asked Which one do you want to use when we read the story? The position of the systems was systematically alternated across days. All participants who progressed to the preference phase always made a choice within $2 \mathrm{~s}$ of being offered the choice. Once the participant had made a choice, the researcher removed the other AAC system and read the entire story to the participant, making use of the same prompting hierarchy as described above to elicit the target combinations. The participant therefore only had one opportunity to choose which system he/she wanted to use during story reading. The same learning criterion as for the intervention phase was set, with a minimum of three sessions conducted.

Maintenance probe. One week after the preference phase had ended, one maintenance probe was conducted for all three conditions. Procedures for the SGD and communication board 
conditions were identical to baseline. For the third story, participants were again given a choice of systems at the beginning of the session, whereafter the entire story was read using the system of their choice. Only the first level of prompting was employed for all three stories.

\section{Procedural integrity}

A speech-language pathologist with postgraduate training in AAC acted as independent observer. She viewed 35 video-recorded sessions (32\% of the total number of sessions) that were randomly selected to amount to at least $20 \%$ per participant per phase. She rated the adherence to procedures according to procedural protocols. These protocols included general procedural steps, such as Experimenter presents the story one picture at a time by positioning the picture within view of the participant, and also steps that were required for each target structure and related to the prompts given, such as Prompt 1: Experimenter draws attention to picture representing target structure (includes strategies such as verbal mand 'look!' and pointing to picture) followed by a pause up to $10 \mathrm{~s}$. Adherence to the latter was rated for each target structure that was presented during the story reading (i.e., 12 times per story). The percentage of steps adhered to was calculated for each session, and ranged from 87-100\%, with mean integrity at $99.7 \%$.

\section{Coding}

The researcher transcribed the participants' responses to the first level of prompting given during story reading from the video recording made on the same day onto a data recording sheet. She classified each response as either correct (i.e. containing both target symbols in the correct order) or not correct. She also captured participants' responses to the other levels of prompting used during the intervention and preference phase for descriptive purposes. 


\section{Data reliability}

The independent observer viewed each of the 35 video sessions selected a second time. She transcribed the participants' graphic symbol responses to the first level of prompting, and classified each response as correct or not correct. Point-by-point agreement of classification of responses was calculated by dividing the total number of agreements by the total number of agreements and disagreements. Agreement on the classification of responses per participant ranged from $92 \%$ to $100 \%$, with a mean agreement of $99.8 \%$.

\section{Data analysis}

The number of correct responses was depicted graphically per participant per condition and per session. Graphs were inspected for trend and level within and across phases. The Wilcoxon ranked pair test (Wilcoxon 1945) was used to determine whether any significant differences occurred between the performance of each of the participants during the communication board and SGD conditions. In order to determine the effect size of the treatment, nonoverlap of all pairs (NAP) was calculated (Parker and Vannest 2009). Parker and Vannest (2009) tentatively suggest that NAP values of .93 and above show large effects, while values between .66 and .92 indicate medium effects. Confidence intervals (CIs; 85\%) were established using the NCSS $8^{\mathrm{TM}}$ ROC curves analysis (NCSS 2012), to determine the certainty with which the effect size could be regarded as true.

\section{Social validity}

After intervention was completed, the researcher selected two video clips of intervention sessions for each participant - one for the SGD and one for the communication board condition. For each condition, the video clip of the session during which the participant produced the most correct combinations was selected. These two clips were shown to each participant's team 
members - parent(s), SLP(s) and class teacher. The order in which videos of the SGD condition versus the communication board condition were shown was counterbalanced across participants. After viewing each clip, team members were requested to rate the effectiveness of the treatment, the usefulness of the AAC system in the future in various contexts and their abilities to implement the system using a 5-point Likert-type rating scale with 10 items. The items were loosely based on Sections A, D and E of the teacher attitude scale (Dada 1999, Dada and Alant 2002), a 21-item scale pertaining to teachers' perceptions of different AAC systems. After completing the rating scale for each video, respondents were asked three open-ended questions in a brief interview pertaining to observed differences between the systems, the advantages and disadvantages of the systems for future use and their preferred system for the participant.

\section{Results}

Figure 1 shows the number of combinations correctly produced in response to the first level of prompting for each of the participants during the baseline, intervention, preference and maintenance phases. Three participants reached criterion in both conditions. Of these, one participant reached criterion in both conditions in the same amount of time, while one reached criterion earlier in the SGD condition and a third reached criterion earlier in the communication board condition. Of the three participants who reached the preference phase, all three consistently preferred the SGD.

\section{Participant 1}

Participant 1 mastered combinations using the SGD and the communication board in the same amount of time, and consistently preferred the SGD during the preference phase. From a stable baseline of zero correct combinations for three consecutive sessions, his performance immediately changed upon introduction of treatment to four correct combinations (33\%) in the 
Participant 1

Baseline

Intervention

Preference

Maintenance probe

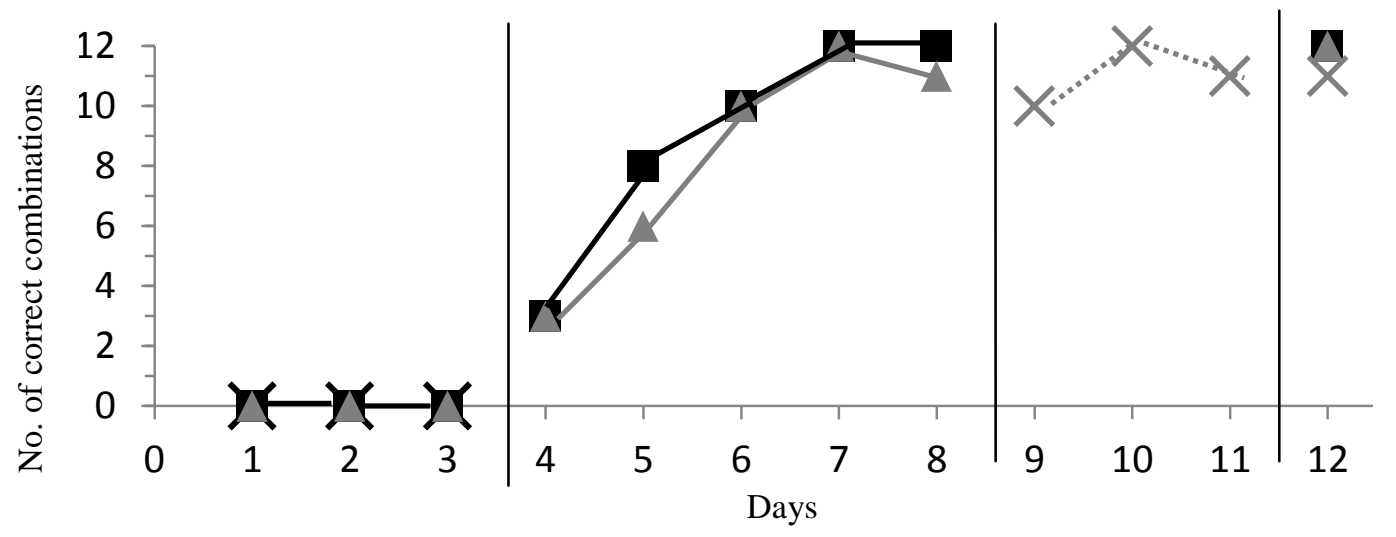

Participant 2

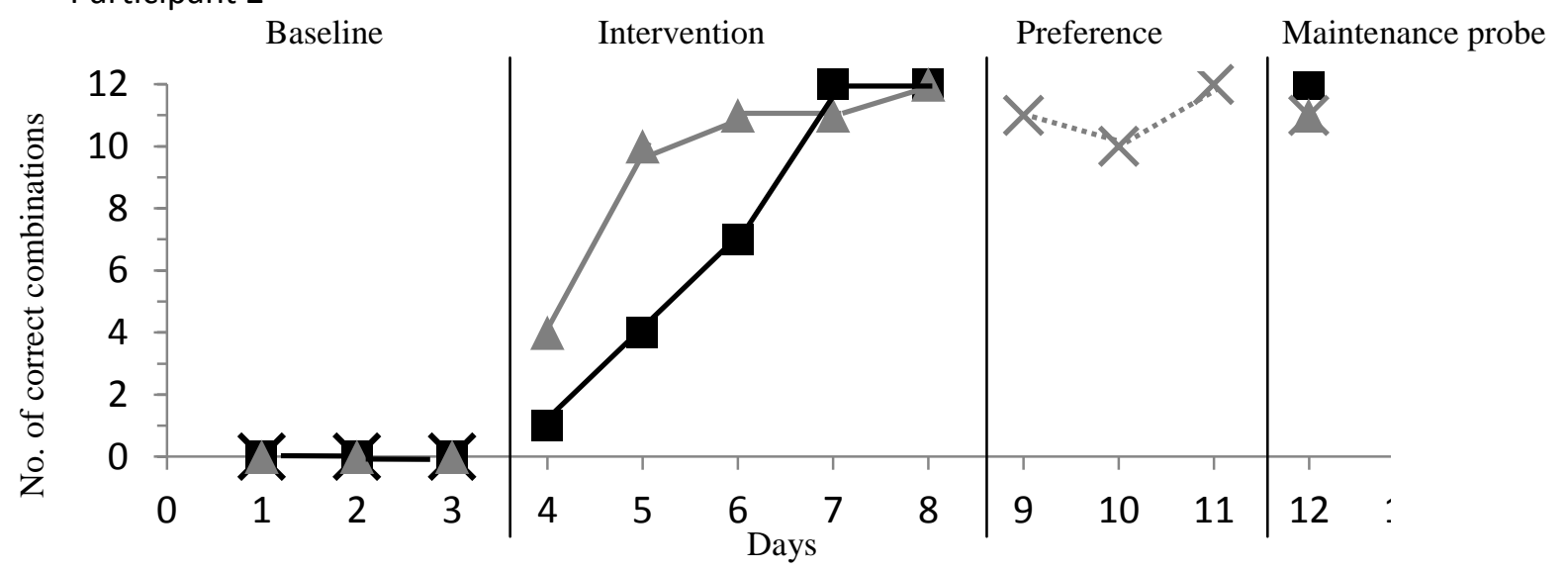

Participant 3

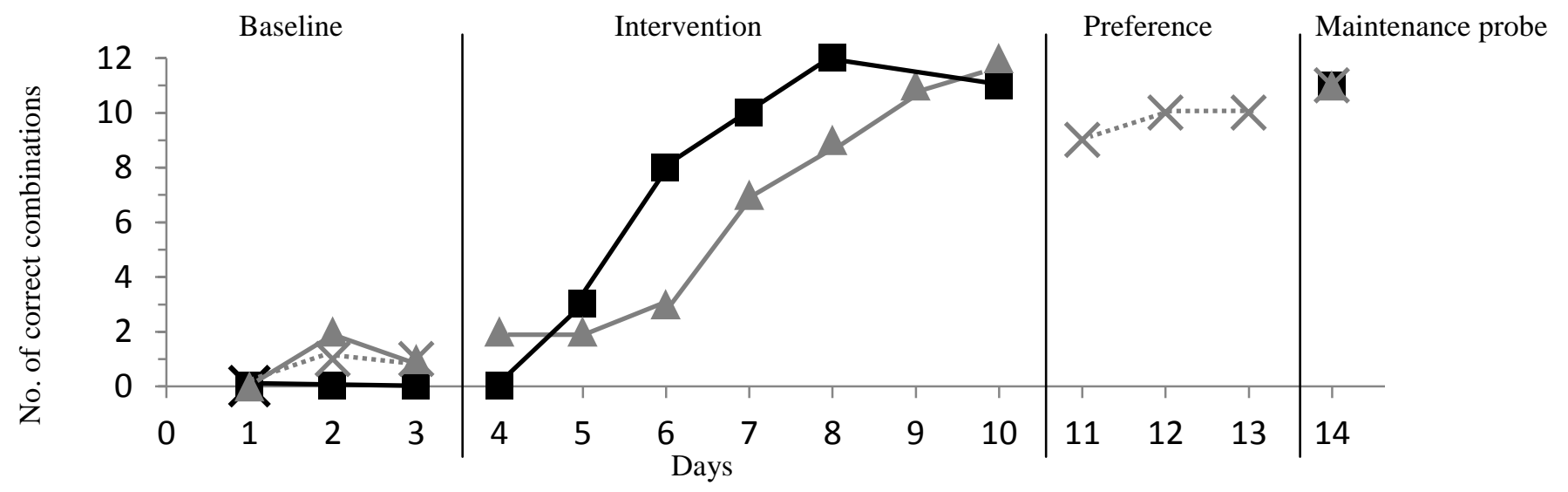

Participant 4

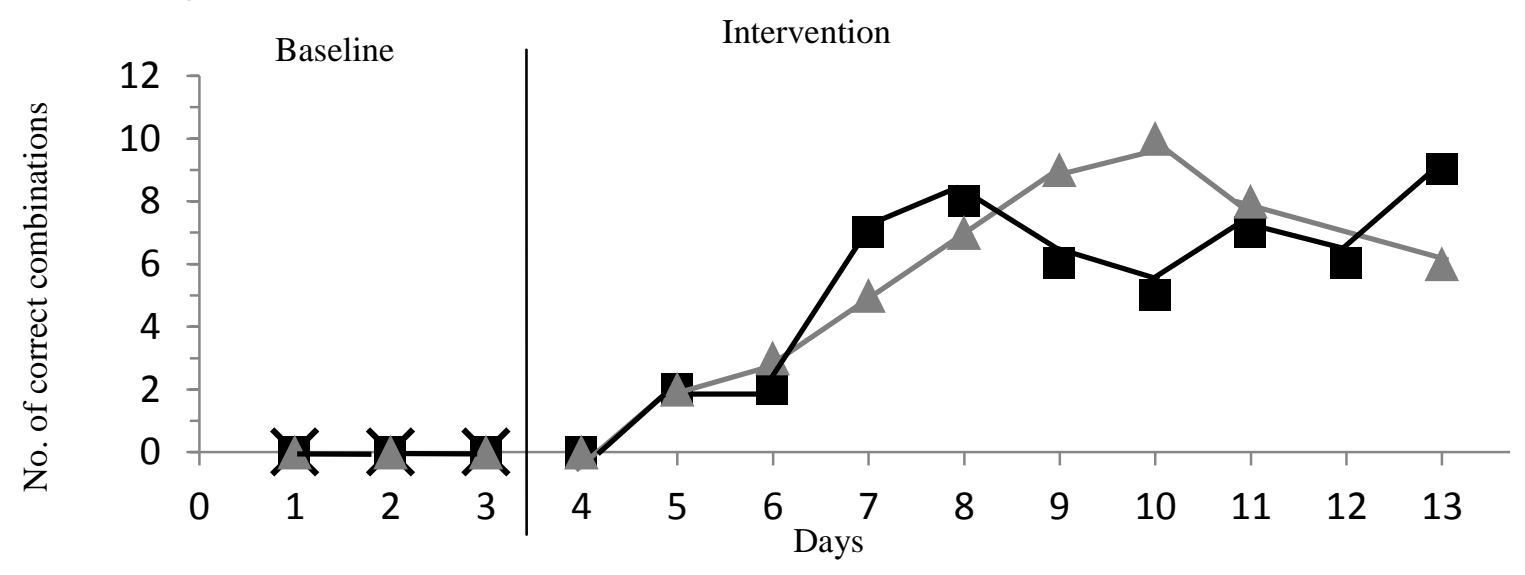

Fig. 1 Number of correct graphic symbol combinations produced by each participant using the communication board or the SGD across sessions 
first session for the SGD condition. Over the next three sessions, performance rapidly increased and the learning criterion was reached during the fourth intervention session. A slight decline from $12(100 \%)$ to $11(92 \%)$ combinations correct was observed from the fourth to the fifth intervention session. Performance during the communication board condition was very similar, with an immediate level change from $0 \%$ at baseline to $33 \%$ correct during the first intervention session. Once again, an accelerating trend was observed and Participant 1 reached learning criterion during the fourth intervention session. A high level of performance (100\% correct) was maintained during the fifth intervention session. The Wilcoxon ranked pair test revealed no significant difference between performance during the two intervention conditions $(\mathrm{z}=1.45, \mathrm{p}=$ .15). NAP scores for both conditions were $100 \%$, indicating strong effects for both conditions.

Participant 1 did not use either device during baseline for the choice condition. During the preference phase, he consistently chose the SGD to use during the story reading activity. He immediately responded with high levels of correct combinations during the preference phase, reaching learning criterion in two sessions. During the maintenance probe conducted after a week, high levels of performance were maintained for all three conditions (SGD, communication board and choice).

\section{Participant 2}

Participant 2 mastered combinations earlier in the SGD condition, and consistently preferred the SGD during the preference phase. His baseline was also stable at $0 \%$ correct for all three conditions (SGD, communication board and choice). During the first intervention session in the SGD condition, his performance increased from 0 to $33 \%$ correct (4 correct combinations). This accelerating trend continued and he reached criterion already in the third session, with $83 \%$ and $92 \%$ correct in the $2^{\text {nd }}$ and $3^{\text {rd }}$ intervention sessions. His performance peaked at $100 \%$ 
correct during the fifth intervention session. In the communication board condition, a slight level change from 0 to $8 \%$ correct during the first session was observed. Performance increased slightly slower than in the SGD condition, with 4 (33\%) and 7 (58\%) correct combinations over the next two sessions. The learning criterion was reached in the fifth intervention session, with $100 \%$ correct performance during the fourth and fifth session. The Wilcoxon ranked pairs test revealed no significant difference between the performance during the SGD versus the communication board condition during the intervention phase $(\mathrm{z}=1.36, \mathrm{p}=.17)$. NAP scores for both conditions were $100 \%$, indicating that both interventions had a strong effect.

During the preference phase, Participant 2 consistently chose the iPad and performed at high levels, reaching the learning criterion after two sessions. The maintenance probe suggests that a high level of performance was maintained after one week on all conditions.

\section{Participant 3}

Participant 3 mastered combinations earlier using the communication board, but also consistently preferred the SGD during the preference phase. She produced two correct combinations during the second and one correct combination during the third baseline session in the SGD condition. No immediate clear level change was observed when treatment was introduced, with two correct combinations during the first two intervention sessions. From the third session, performance steadily increased and the learning criterion was reached during the seventh intervention session with $11(92 \%)$ and 12 (100\%) correct combinations produced. No correct combinations were produced in the communication board condition during baseline. Performance remained at $0 \%$ correct during the first intervention session, after which it increased to $3(25 \%), 8(67 \%), 10(83 \%)$ and $12(100 \%)$ correct during the next four sessions - a more rapid increase than that noted during the SGD condition. The learning criterion was reached 
during the fifth session. A monitoring probe was conducted during Day 9, and performance dropped slightly to $11(92 \%)$ correct combinations. The Wilcoxon ranked pair test was conducted to compare performance on those days where both conditions were administered. Results revealed no significant difference between the performance in the two conditions ( $\mathrm{z}=$ $1.23, \mathrm{p}=.2$ ). The NAP score was $95 \%$ for the SGD condition, indicating a strong treatment effect, $85 \%$ CIs [0.75, 0.99]. For the communication board condition, a NAP score of $92 \%$ was obtained, with $85 \%$ CIs $[0.63,0.98]$. This value suggests a medium effect.

During the choice condition, Participant 3 produced one correct combination using the SGD during the second and third baseline sessions. During the preference phase, Participant 3 chose the SGD 100\% of the time. Her performance was at relatively high levels, and she reached the learning criterion after three sessions, obtaining 9 (75\%) correct combinations in the first session and $10(83 \%)$ correct combinations during the following two sessions. She maintained a high level of performance during the maintenance probe, with $11(92 \%)$ correct combinations for all three conditions.

\section{Participant 4}

Participant 4 did not reach the learning criterion in any of the conditions. He did not produce any correct combinations during baseline, and also did not do so during the first intervention session in either the SGD or communication board condition. His performance in the SGD condition steadily improved over the following six sessions to peak at $10(83 \%)$ correct combinations on Day 10. His performance decreased to $8(66 \%)$ correct during the next session. On Day 12, Participant 4 sustained a small injury during break time, and, as the SGD-based intervention session had been scheduled after break time, he was unable to attend it. On Day 13, performance dropped again to 6 (50\%) correct. The learning criterion was not met within this 
time. Performance during the communication board condition showed an overall increase during the sessions conducted from Days 5 to 13, although a decelerating trend could be seen from Days 8 to 10 , and also 11 to 12 . His highest performance for this condition occurred during the last session (9 [75\%] correct combinations). Once again the learning criterion was not reached. The Wilcoxon ranked pairs test revealed no significant differences between the performance during the intervention phase $(\mathrm{z}=1.32, \mathrm{p}=.18)$. NAP scores suggest strong treatment effects for both the SGD condition $(94 \%, 85 \%$ CI $[0.75,0.99])$ and the communication board condition $(95 \%, 85 \%$ CI $[0.63,0.98])$. An error analysis was done in order to determine the types of errors which Participant 4 made during intervention. Overall, he responded incorrectly to the first level of prompting $54 \%$ of the time in the SGD condition, and $56 \%$ of the time in the communication board condition. His incorrect responses consisted mostly of a reversal of the two symbols (29\% of responses in the SGD condition and $20 \%$ of responses in the communication board condition). Due to the fact that the learning criterion was not reached on either condition, Participant 4 did not receive the preference phase.

\section{Social validity}

A total of 14 team members completed the rating and the interviews (five parents, five SLPs and four class teachers). Results indicated that both treatments were perceived as very effective and as useful to very useful in future. Respondents felt confident about their ability to implement both systems but indicated a need for further training - more so for the iPad with the GoTalk Now application than the communication board. Of the respondents, 12 preferred the iPadwith the GoTalk Now application for future use, one preferred the communication board and one participant felt that both should be implemented. Preferences of the team members of participants who had progressed to the preference phase coincided with those of the children 
$91 \%$ of the time. Respondents based their preference on the voice output feature of the iPad with the GoTalk Now application with the benefits of greater intelligibility and sound awareness for literacy training, and also the perception that technology use increased the participants' motivation and favorable perceptions from communication partners. The fact that adding new vocabulary to the GoTalk Now application did not require additional resources such as paper, software and a printer was also seen as an advantage. Disadvantages of the iPad that were mentioned included its fragility, the bigger likelihood that it may get stolen and the perception that it was difficult to program.

\section{Discussion}

The first aim of the study was to compare the efficacy of two AAC strategies in promoting the production of two-symbol combinations of children with severe motor speech disorders during story reading. Intervention entailed the use of a prompting hierarchy to elicit two-symbol productions using either an iPad with the GoTalk Now application or a communication board. Results indicate that all participants increased their productions of twosymbol combinations after intervention commenced in both conditions, confirming results from previous studies where children with limited speech learned to produce symbol combinations with communication boards (Binger et al. 2008; 2010; Nigam et al. 2006, Tönsing et al. 2014) or SGDs (Binger et al. 2008; 2010). No differences were noted in the effectiveness of either strategy as determined by the attainment of a learning criterion, with Participants $1-3$ reaching criterion in both conditions within the maximum number of sessions, whereas Participant 4 did not reach the learning criterion in either condition within 10 sessions. Comparisons between the number of correct combinations produced by each participant on each day for each condition using the Wilcoxon ranked pairs test did not reveal any statistically significant differences. 
Slight individual differences were noted in the efficiency with which two of the participants learnt the combinations in the two conditions, with Participant 2 reaching the learning criterion earlier in the SGD condition (three sessions) than in the communication board condition (five sessions), while Participant 3 reached the learning criterion earlier in the communication board condition (five sessions) than the SGD condition (seven sessions). Taken together, these results suggest that both systems are similarly effective and efficient in promoting the production of graphic symbol combinations. Contrary to my hypothesis, the additional speech output from the SGD did not seem to provide a learning advantage. The results are in agreement with those found in most studies comparing the effect of SGD versus non-electronic AAC system-based interventions on requesting skills. Although one study (Beck, Stoner, Bock and Parton 2008) found a consistent advantage of a non-electronic system (picture exchange) over an SGD in promoting requesting skills, six other studies found no differences or had mixed results, with some participants performing better with an SGD while others performed better with nonelectronic AAC systems (Bock, Stoner, Beck, Hanley and Prochnow 2005; Boesch et al. 2013; Cannella-Malone, DeBar and Sigafoos 2009; Sigafoos, Green, Payne and Son 2009; Sigafoos et al. 2005; Son, Sigafoos, O'Reilly and Lancioni 2006). Similar to other studies, the intervention procedure was very structured, and responses were elicited and corrected until participants produced correct combinations. The intervention procedure (structured prompting) may have been effective enough to negate any potential differential influence of the system used.

Although Participant 4 learnt to produce symbol combinations, he did not reach criterion within the 10 sessions. His skill profile (see Table 1) did not differ significantly from the other participants, although he was the youngest. He did seem to be more distractible and impulsive than the other participants, and the lapses in performance in both conditions observed between 
Days 9 to 13 may have resulted from becoming uninterested in the story reading activity. $\mathrm{He}$ may have benefitted from a change in procedures and from intervention strategies specifically targeting his tendency to reverse symbols.

During baseline, participants were provided with both the iPad and the communication board for one of the stories (choice condition). Participants 1, 2 and 4 did not make use of either system, while Participant 3 produced two correct combinations using the iPad during baseline. During the preference phase conducted with Participants 1-3, all participants chose the iPad on all occasions. Although the amount of opportunities given to make a choice between systems is less than the amount reported in other studies (see Van der Meer et al. 2011, for a review) the consistency with which participants made a choice suggests that they indeed preferred the iPad. This result is consistent with the finding in the review by Van der Meer et al. (2011) where preference assessments done in seven studies revealed that most participants (67\%) preferred the SGD above other systems or strategies. As in other studies, it is hard to determine what the exact reasons for the preference were. All four participants reportedly enjoyed playing games on their parents' mobile phones, and it is possible that they therefore had a positive association with technology. The voice output feedback as well as the visual feedback obtained by activating a cell (cell changes to a darker colour while touched) may also have been reinforcing. Participants 1, 2 and 4 had not used the iPad for communication purposes before, although they had had previous exposure to communication boards. The iPad's novelty effect may have affected the preference of Participants 1 and 2.

Team perceptions regarding preference (although only assessed in a limited way) coincided mostly with those of the children. Team members gave various valid reasons for their preference, indicating that they had considered their choice. Although the small scale of this 
investigation precludes generalization of these findings, they are nevertheless encouraging, as an alignment in preferences between the person using the device and his/her team members seems to provide a good foundation for the implementation of the preferred AAC system. Team member preference for an iPad-based AAC system over a non-electronic AAC system were also reported in Flores et al. (2012). The results are also in line with recent findings that children aged 9;0 to $12 ; 11$ had a more positive attitude towards a peer using an iPad-based text-to-speech application as compared to the same peer using a paper-based communication board (Horn 2014).

\section{Clinical implications}

Results of the study suggest that children with developmental disabilities and severe motor speech disorders can be taught to produce graphic symbol combinations using either the iPad with a speech generating application or a communication board. There is no evidence that the provision of a low-cost communication board (which is often more attainable in resourcelimited environments such as South Africa) would disadvantage a child in learning symbol combinations. In spite of comparable performance during the story reading activity using either system, all participants that progressed to the preference phase consistently chose the SGD. In other preference assessments reported in the literature, performance also did not predict preference (for a review see Van der Meer et al. 2011). Service providers are therefore encouraged not to assume preference based on performance, but to include preference assessments as part of the information gathering strategies to inform the choice of a certain AAC system.

The selection of an appropriate AAC system needs to take many factors into account. Besides preference and the ease with which the system promotes the production of utterances of 
increasing complexity serving a variety of communication functions, service providers and families also need to consider, amongst others, the intelligibility of the system to a variety of partners, the preferences of the partners, the cost, durability, portability as well as the ease of maintaining and expanding the system (Quist and Lloyd 1997). The iPad with the GoTalk Now application offers benefits such as voice output. While the intelligibility of synthetic speech varies and is influenced by a number of factors (Koul 2003), recent synthetic voices have improved intelligibility (Garg and Singhal 2014, Henton 2013). Graphic symbol-based systems without voice output rely on the ability of pre- or non-literate partners to interpret the meaning of the symbols, yet this meaning is not necessarily always easy to guess (Dada, Huguet and Bornman 2013). Voice output can be an important tool for gaining a partner's attention, especially for children who have little control over their own vocalizations (Soto and SeligmanWine 2003). Communication over a distance is possible, while a communication board necessitates greater proximity with the partner (Boesch et al. 2013). Voice output might promote greater communicative autonomy, as partners would be likely to 'voice over' (or speak out loud) the message conveyed by a person using a communication board, whereas this function is taken over by the voice output of the SGD. At the same time, Brekke and Von Tetzchner (2003) in their case study discussion of a young boy relying on graphic-symbol-base AAC systems, remarked on a tendency of partners to expect independent use when technology was involved, whereas partners tended to be more supportive and actively involved in the construction of messages when boards and books were used. High cost and lack of portability have been suggested as two main disadvantages for many SGDs (Boesch et al. 2013). Although the iPad with the GoTalk Now application is less costly than many dedicated SGDs, it still seems more expensive than a paper-based system such as a collection of communication boards. However, 
boards that are made using commercially available symbols such as PCS necessitate the symbol software, a computer, and a printer. These costs may not be obvious when considering the paper-based product. Also, each new board requires additional paper and printing ink, as well as possible lamination for durability. Costs are therefore incurred every time the vocabulary is expanded, whereas vocabulary expansion using various apps with extensive symbol libraries do not require extra expenses when new vocabulary is programmed.

Due to inherent differences between electronic and non-electronic AAC systems, it is likely that communication situations arise in which use of either the one or the other is not possible or impractical. An iPad may be at risk of being broken when taken out onto the playground, while the use of a board may fail to get the teacher's attention in a busy classroom. Concurrent implementation of a non-electronic and electronic system with identical symbols and symbol arrangement may be beneficial to allow children to successfully participate in a variety of communication situations (Boesch et al. 2013). In the current study, children successfully used both an electronic and a non-electronic system in an alternating fashion, suggesting that such a concurrent implementation of interchangeable systems may be possible.

\section{Limitations and directions for further research}

A major limitation of the current study was the limited time available for data collection. Researcher commitments and the commencement of the school holidays limited the time available for data collection. One of the four participants did not reach the learning criterion in either condition within the time available. He may have benefitted from amendments to the intervention procedures to specifically address his tendency to reverse the two target symbols. Due to time constraints, this was not possible. Furthermore, only one maintenance probe was done. Maintenance data is therefore too limited to draw any definite conclusions about the 
participants' ability to retain their symbol combination skills.

Participant 3 produced some correct symbol combinations during the baseline phase in the SGD and choice conditions. As a result, the intervention effect for the SGD condition is less convincing. Correct responses during baseline on the intervention items allocated to one condition and not those allocated to another condition may cast doubt on the equivalence of the intervention sets. However, Participant 3 progressed more rapidly in the communication board condition despite the fact that, during baseline, she did not produce any correct responses on intervention items allocated to this condition. It seems, therefore, that other factors rather than the lower difficulty level of the intervention items may have encouraged her responses during baseline. The iPad may have encouraged spontaneous use more than the communication board. Findings are limited as only four children participated in the study. Generalization across instructors and contexts was also not investigated, and only two types of semantic relations (agent-action and attribute-entity) were targeted in intervention. The production of combinations specifically targeted in intervention cannot be regarded as evidence that children can flexibly and meaningfully combine symbols. Producing multisymbol combinations can be regarded as a stepping stone towards the emergence of syntax, and therefore represents a linguistic skill that can increase communicative competence across various contexts, partners and communication functions. It would be important to investigate how this skill can be fostered in different environments by different partners using different AAC systems.

Successful productions of the symbol combinations may in large part be attributed to the structured prompting hierarchy. It may be that more naturalistic intervention techniques, such as the System for Augmenting Language (SAL; Romski and Sevcik 1996) or Aided Language Stimulation (AiLS; Goossens 1989) where responses are less pertinently probed for may reveal 
clearer differences between an SGD and a paper-based communication system, as the child's own motivation to use the system may have a bigger role to play than in intervention situations where responses are externally prompted for and reinforced (Light et al. 2002).

It would furthermore be of interest to describe and compare how interactions proceed when one partner uses either an SGD or a paper-based AAC system. Talk-in-interaction research using conversation analysis (Higginbotham and Engelke 2013) may provide some insight as to how the interactional dynamics of a conversational dyad differ when different AAC systems are used. Parameters such as turn-taking, repair strategies and co-construction could be investigated.

Preference assessments for both children and team members were limited, and team member preferences were obtained before team members had extensive experience in implementing both or at least one of the systems (some had experience in implementing communication boards but none had implemented the iPad with the GoTalk Now application). Since preferences may change over time and also with increased exposure (Van der Meer et al. 2011 ; 2013), it would be helpful to assess these more regularly before and also during intervention and implementation of the systems in natural contexts.

\section{Acknowledgements}

This research project was funded by the National Research Foundation (NRF) of South Africa and the Research Development Programme from the University of Pretoria. Opinions expressed and conclusions arrived at, are those of the author and are not necessarily to be attributed to the NRF or the University of Pretoria. The author would like to thank the children, their families, and the school staff for making the study possible. 


\section{Conflict of interest}

The author reports no conflict of interest. The author alone is responsible for the content and writing of this paper.

\section{References}

Bates, E., Dale, P. S., \& Thal, D. (1995). Individual differences and their implications for theories of language development. In P. Fletcher \& B. MacWhinney (Eds.), Handbook of child language (pp. 96-151). Oxford: Basil Blackwell.

Beck, A. R., Stoner, J. B., Bock, S. J., \& Parton, T. (2008). Comparison of PECS and the use of a VOCA: a replication. Education and Training in Developmental Disabilities, 43(2), 198-216.

Binger, C., Kent-Walsh, J., Berens, J., Del Campo, S., \& Rivera, D. (2008). Teaching Latino parents to support the multi-symbol message productions of their children who require AAC. Augmentative and Alternative Communication, 24(4), 323-38. doi:10.1080/07434610802130978

Binger, C., Kent-Walsh, J., Ewing, C., \& Taylor, S. (2010). Teaching educational assistants to facilitate the multisymbol message productions of young students who require augmentative and alternative communication. American Journal of Speech-Language Pathology / American Speech-Language-Hearing Association, 19(2), 108-120. doi:10.1044/1058-0360(2009/09-0015)

Binger, C., \& Light, J. (2007). The effect of aided AAC modeling on the expression of multi-symbol messages by preschoolers who use AAC. Augmentative and Alternative Communication, 23(1), 30-46. doi:10.1080/07434610600807470

Binger, C., \& Light, J. (2008). The morphology and syntax of individuals who use AAC : research review and implications for effective practice. Augmentative and Alternative Communication, 24(2), 123-138. doi:10.1080/07434610701830587

Blackstone, S. W., Williams, M. B., \& Wilkins, D. P. (2007). Key principles underlying research and practice in AAC. Augmentative and Alternative Communication, 23(3), 191-203. doi:10.1080/07434610701553684 
Bock, S. J., Stoner, J. B., Beck, A. R., Hanley, L., \& Prochnow, J. (2005). Increasing functional communication in non-speaking preschool children: comparison of PECS and VOCA. Education and Training in Developmental Disabilities, 40(3), 264-278.

Boesch, M. C., Wendt, O., Subramanian, A., \& Hsu, N. (2013). Comparative efficacy of the picture exchange communication system (PECS) versus a speech-generating device : effects on requesting skills. Research in Autism Spectrum Disorders, 7(3), 480-493. doi:10.1016/j.rasd.2012.12.002

Bortz, M. (1997). South African language assessments. Ponteland, United Kingdom: STASS Publications.

Brekke, K. M., \& Von Tetzchner, S. (2003). Co-construction in graphic language development. In S. Von Tetzchner \& N. Grove (Eds.), Augmentative and alternative communication: developmental issues (pp. 176-210). London, United Kingdom: Whurr.

Brown, R. (1973). A first language: the early stages. London, United Kingdom: George Allen \& Unwin.

Bruno, J., \& Trembath, D. (2006). Use of aided language stimulation to improve syntactic performance during a weeklong intervention program. Augmentative and Alternative Communication, 22(4), 300-13. doi: $10.1080 / 07434610600768318$

Cannella-Malone, H. I., DeBar, R. M., \& Sigafoos, J. (2009). An examination of preference for augmentative and alternative communication devices with two boys with significant intellectual disabilities. Augmentative and Alternative Communication, 25, 262-273. doi:10.3109/07434610903384511

Carrow-Woolfolk, E. (1999). Test for auditory comprehension of language (4th ed.). Austin, TX: Pro-Ed.

Dada, S. (1999). Teachers' attitudes towards children with LNFS using two AAC devices. University of Pretoria. Retrieved from http://upetd.up.ac.za/thesis/available/etd-08022006-142253/

Dada, S., \& Alant, E. (2002). A comparative study of the attitudes of teachers at special and educationally inclusive schools towards learners with little or no functional speech using communication devices. South African Journal of Education, 22(3), 213-218.

Dada, S., Huguet, A., \& Bornman, J. (2013). The iconicity of picture communication symbols for children with English additional language and mild intellectual disability. Augmentative and Alternative Communication, 29(4), 360-73. doi:10.3109/07434618.2013.849753

Dowden, P. (1997). Augmentative and alternative communication: decision making for children with severely unintelligible speech. Augmentative and Alternative Communication, 13, 48-58. 
Dunn, L. M., \& Dunn, D. M. (2007). Peabody picture vocabulary test (4th ed.). San Antonio: Pearson.

Fitzgerald, E. (1959). Straight language for the Deaf. Washington, DC: The Volta Bureau.

Flores, M., Musgrove, K., Renner, S., Hinton, V., Strozier, S., Franklin, S., \& Hil, D. (2012). A comparison of communication using the Apple iPad and a picture-based system. Augmentative and Alternative Communication, 28(2), 74-84. doi:10.3109/07434618.2011.644579

Garg, M., \& Singhal, R. (2014). Speech re-synthesis from spectrogram image through sinusoidal modelling. In Advances in Computing, Communications and Informatics (ICACCI, 2014 International Conference) (pp. 2757-2761). Delhi: Institute of Electrical and Electronic Engineers.

Gevarter, C., O’Reilly, M. F., Rojeski, L., Sammarco, N., Lang, R., Lancioni, G. E., \& Sigafoos, J. (2013). Comparing communication systems for individuals with developmental disabilities : a review of single-case research studies. Research in Developmental Disabilities, 34(12), 4415-4432. doi:10.1016/j.ridd.2013.09.017

Goossens, C. (1989). Aided communication intervention before assessment: a case study of a child with cerebral palsy. Augmentative and Alternative Communication, 5, 14-26. doi:10.1080/07434618912331274926

Henton, C. (2012). Text-to-Speech Synthesis Development. The Encyclopedia of Applied Linguistics. Wiley Online Library. doi:10.1002/9781405198431.wbeal1207

Higginbotham, D. J., \& Engelke, C. R. (2013). A primer for doing talk-in-interaction research in Augmentative and Alternative Communication. Augmentative and Alternative Communication, 29(1), 3-19. doi: $10.3109 / 07434618.2013 .767556$

Horn, T. (2014). Children's attitudes towards interaction with an unfamiliar peer with little or no functional speech: Comparing high- and low-technology devices. Universtiy of Pretoria.

Kaufman, A. S., \& Kaufman, N. L. (2004). Kaufman Brief Intelligence Test ( $2^{\text {nd }}$ ed.). San Antonio, TX: PEarson.

Kent-Walsh, J., \& McNaughton, D. (2005). Communication partner instruction in AAC: present practices and future directions. Augmentative and Alternative Communication, 21(3), 195-204. doi:10.1080/07434610400006646

Koul, R. (2003). Synthetic speech perception in individuals with and without disabilities. Augmentative and Alternative Communication, 19(1), 49-58. doi:10.1080/0743461031000073092

Light, J. C., Parsons, A. R., \& Drager, K. (2002). “There's more to life than cookies.” Developing interactions for social closeness with beginning communicators who use AAC. In J. Reichle, D. R. Beukelman, \& J. C. Light 
(Eds.), Exemplary pratices for beginning communicators: Implications for AAC (pp. 187-218). Baltimore, MD: Paul H. Brookes.

Light, J., \& Drager, K. (2007). AAC technologies for young children with complex communication needs: state of the science and future research directions. Augmentative and Alternative Communication, 23(3), $204-16$. doi:10.1080/07434610701553635

NCSS (2012). [Computer software]. Kaysville, UT: NCSS LLC.

Nigam, R., Schlosser, R. W., \& Lloyd, L. L. (2006). Concomitant use of the matrix strategy and the mand-model procedure in teaching graphic symbol combinations. Augmentative and Alternative Communication, 22(3), 160-77. doi:10.1080/07434610600650052

Parker, R. I., \& Vannest, K. (2009). An improved effect size for single-case research: nonoverlap of all pairs. Behavior Therapy, 40(4), 357-67. doi:10.1016/j.beth.2008.10.006

Quist, R., \& Lloyd, L. L. (1997). Principles and uses of technology. In L. L. Lloyd, D. R. Fuller, \& H. H. Arvidson (Eds.), Augmentative and alternative communication: a handbook of Principles and practices (pp. 107-126). Needham Heights: Allyn \& Bacon.

Romski, M. A., \& Sevcik, R. A. (1988). Augmentative and alternative communication systems : considerations for individuals with severe intellectual disabilities. Augmentative and Alternative Communication, 4(2), 83-93. doi:10.1080/07434618812331274667

Romski, M. A., \& Sevcik, R. A. (1996). Breaking the speech barrier: language development through augmented means. Baltimore, MD: Paul H. Brookes.

Romski, M. A., Sevcik, R. A., \& Adamson, L. B. (1997). Framework for studying how children with developmental disabilities develop language through augmented means. Augmentative and Alternative Communication, 13(3), 172-178. doi:10.1080/07434619712331277988

Schlosser, R. W. (2003). Roles of Speech Output in Augmentative and Alternative Communication : Narrative Review. Augmentative and Alternative Communication, 19(1), 5-27. doi:10.1080/0743461032000056450

Sigafoos, J., Green, V. A., Payne, D., \& Son, S. (2009). A Comparison of picture exchange and speech-generating devices : acquisition, preference, and effects on social interaction. Augmentative and Alternative Communication, 25, 99-109. doi:10.1080/07434610902739959 
Sigafoos, J., O’Reilly, M. F., Ganz, J. B., Lancioni, G. E., \& Schlosser, R. W. (2005). Supporting self-determination in AAC interventions by assessing preference for communication devices. Technology and Disability, 17, $143-153$.

Son, S., Sigafoos, J., O’Reilly, M. F., \& Lancioni, G. E. (2006). Comparing two types of augmentative and alternative communication systems for children with autism. Pediatric Rehabilitation, 9(4), 389-385. doi:10.1080/13638490500519984

Soto, G., \& Seligman-Wine, J. (2003). Child-driven development of alternative communciation: a case study. In S. Von Tetzchner \& N. Grove (Eds.), Augmentative and alternative communication: developmental issues (pp. 211-228). London, United Kingdom: Whurr.

Sutton, A., Soto, G., \& Blockberger, S. (2002). Grammatical issues in graphic symbol communication. Augmentative and Alternative Communication, 18, 192-204.

Tönsing, K. M., Dada, S., \& Alant, E. (2014). Teaching graphic symbol combinations to children with limited speech during shared story reading. Augmentative and Alternative Communication (Baltimore, Md. : 1985), 30(4), 279-97. doi:10.3109/07434618.2014.965846

Van der Meer, L., Kagohara, D., Roche, L., Sutherland, D., Balandin, S., Green, V. A., ... Sigafoos, J. (2013). Teaching multi-step requesting and social communication to two children with autism spectrum disorders with three AAC options. Augmentative and Alternative Communication, 29(3), 222-234. doi: $10.3109 / 07434618.2013 .815801$

Van der Meer, L., Sigafoos, J., O’Reilly, M. F., \& Lancioni, G. E. (2011). Assessing preferences for AAC options in communication interventions for individuals with developmental disabilities : a review of the literature. Research in Developmental Disabilities, 32, 1422-31. doi:10.1016/j.ridd.2011.02.003

Wetherby, A. M., Watt, N., Morgan, L., \& Shumway, S. (2007). Social communication profiles of children with autism spectrum disorders late in the second year of life. Journal of Autism and Developmental Disorders, 37 , 960-975. doi:10.1007/s10803-006-0237-4

Wilcoxon, F. (2014). Individual comparisons by ranking methods. Biometrics Bulletin, 1(6), 80-83.

Wolery, W., Gast, D. L., \& Hammond, D. (2010). Comparative intervention designs. In D. Gast (Ed.), Single subject research methodologies in behavioral sciences (pp. 329-381). New York, NY: Routledge. 


\section{Appendix}

Arrangement of Symbols on Communication Boards and GoTalk Now Pages
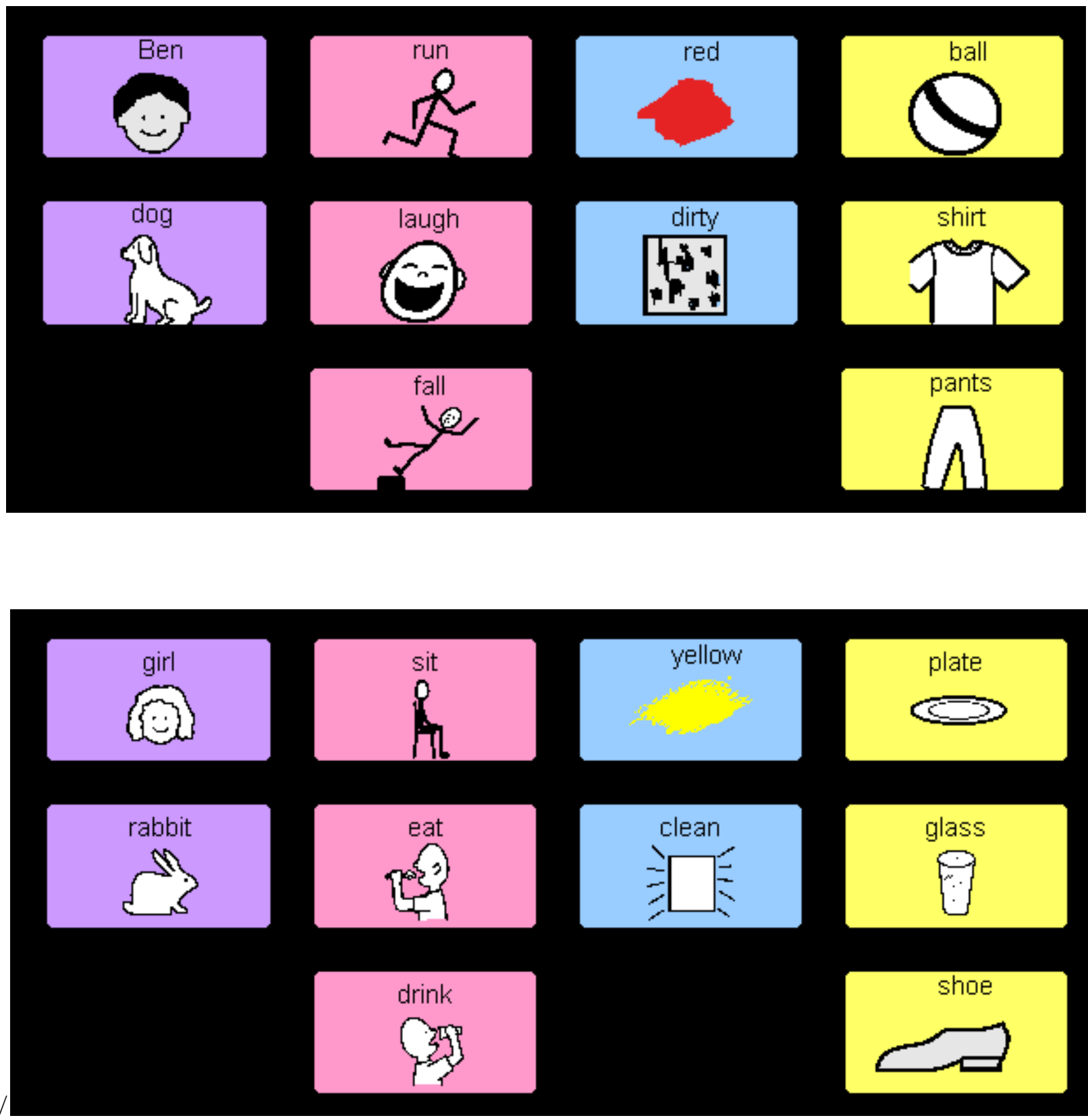


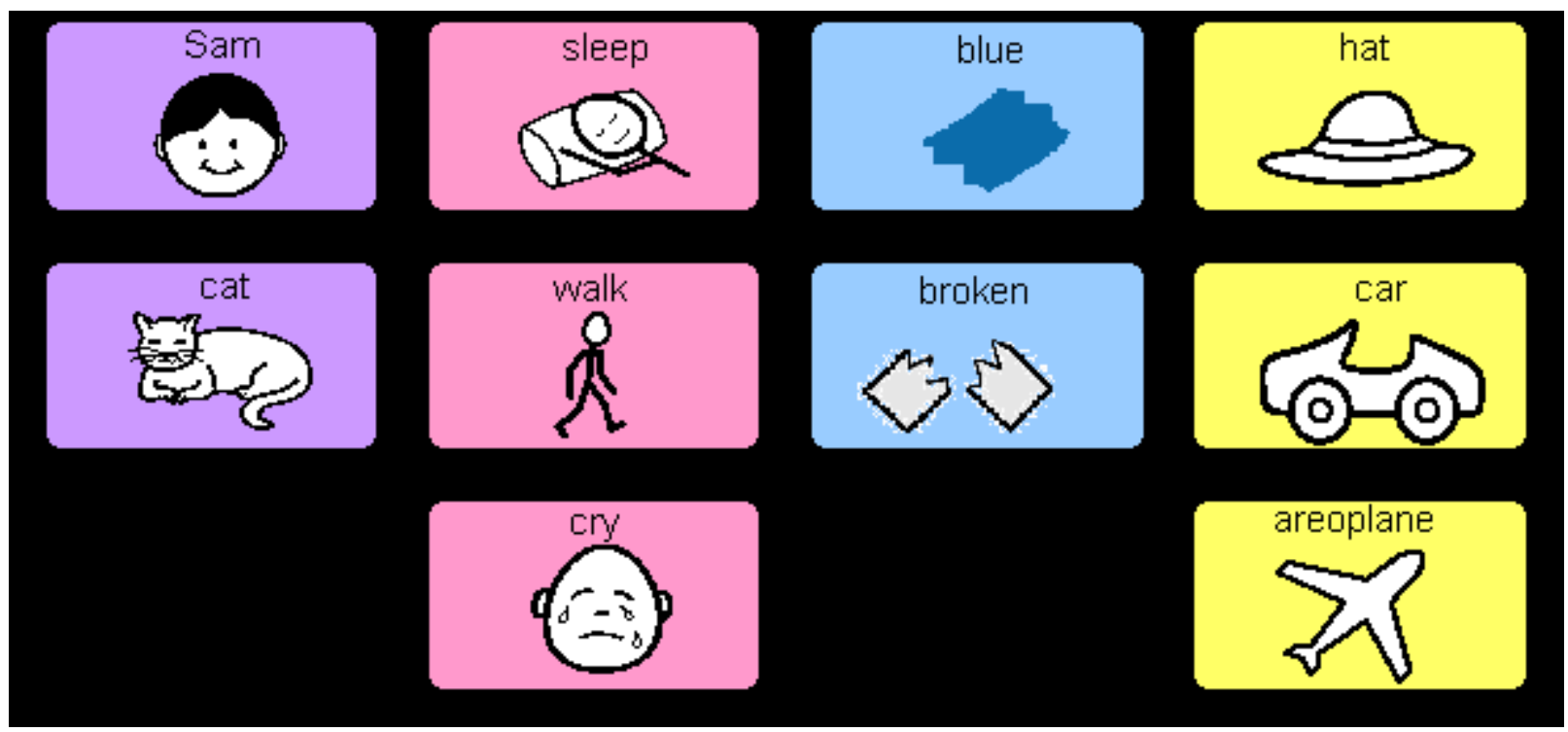

